\title{
Molecular prognostic factors in rectal cancer treated by preoperative chemoradiotherapy
}

\author{
TAEK-KEUN NAM ${ }^{1}$, JI-SHIN LEE ${ }^{2}$, HYEONG-ROK KIM ${ }^{3}$, \\ SUNG-JA AHN ${ }^{1}$, JU-YOUNG SONG ${ }^{1}$ and MEE SUN YOON ${ }^{1}$ \\ Departments of ${ }^{1}$ Radiation Oncology, ${ }^{2}$ Pathology and ${ }^{3}$ Surgery, \\ Chonnam National University Medical School, Gwangju, Korea
}

Received June 12, 2009; Accepted September 24, 2009

DOI: $10.3892 /$ ol_00000004

\begin{abstract}
The present study evaluated the expression of $\mathrm{p} 53, \mathrm{pRb}, \mathrm{hMLH} 1$ and MDM2 prior to preoperative chemoradiotherapy (CRT) in patients with rectal cancer, and attempted to determine any correlation with treatment outcome. Forty-five patients with available pretreatment biopsy tissues and who received preoperative CRT were enrolled in this study. Preoperative CRT consisted of a median 50.4 Gy and 2 cycles of concurrent administration of 5-fluorouracil + leucovorin. Surgery was performed approximately seven weeks after CRT. Protein expression in formalin-fixed paraffin-embedded biopsy specimens was assessed by immunohistochemistry. A positive expression of p53, pRb, hMLH1 and MDM2 was found in 40, 46.7, 40 and $66.7 \%$ of the tissue specimens, respectively. The 5-year overall (OS), disease-free (DFS) and locoregional recurrence-free survival (LRFS) rates for patients included in the study were $71.3,66.1$ and $60.9 \%$, respectively. p53 expression presented a significantly different $\mathrm{OS}$ (positive vs. negative, 45.8 vs. $86.2 \%$; $\mathrm{p}=0.02$ ). However, the expression of $\mathrm{pRb}$, hMLH1 and MDM2 was not significant for OS. The expression of p53 was a borderline significant prognostic factor for DFS and for LRFS. Age, p53 and MDM2 expression were significant factors in the multivariate analysis performed for OS with 12 covariates, including 8 clinicopathological parameters and 4 proteins. No significant factor affected DFS or LRFS in the multivariate analysis. We suggest that the expression of p53 is a potential marker of survival. Determinations of this protein expression may be useful for selecting candidates from rectal cancer patients for more tailored treatment.
\end{abstract}

\section{Introduction}

Preoperative chemoradiotherapy (CRT) has been used extensively for locally advanced rectal cancer (LARC).

Correspondence to: Dr Taek-Keun Nam, Department of Radiation Oncology, Chonnam National University Hwasun Hospital, 160 Ilsimri, Hwasun-eup, Hwasun-gun, Jeonnam 519-809, Korea

E-mail: tknam@chonnam.ac.kr

Key words: rectal neoplasms, preoperative chemoradiotherapy, p53, pRb, hMLH1, MDM2
As compared with conventional postoperative CRT, many studies have reported improved local tumor control, increased respectability, decreased toxicities and a higher sphincterpreservation rate (1-4). Preoperative CRT is also able to reduce tumor volume significantly. Kim et al have reported the mean percent volume reduction rate of primary tumors as $66.5 \%$ using magnetic resonance volumetry performed before and after CRT (5). Although the down-staging rate of primary tumors is approximately $50-60 \%$ for the use of preoperative CRT $(1,2,4)$, a significant proportion of patients did not achieve a sufficient response to preoperative CRT, even with a long interval from CRT to surgery. To identify patients that may achieve a favourable response to treatment and who are at risk for treatment failure, as well as to predict survival prognosis, a number of molecular markers were recently investigated in patients with LARC. These molecular markers would allow for the delivery of individualized treatment regimens. Studies were performed on LARC patients treated with preoperative CRT. These studies have reported that expression patterns of biomarkers including Bax, epidermal growth factor receptor, p21, Ki-67 and caveolin-1 were correlated with response to CRT, local tumor control or survival (6-10).

We investigated the expression of molecular markers including p53, pRb, hMLH1 and MDM2.p53 activates genes that induce apoptosis in DNA-damaged cells (11). In view of survival prognosis, no studies have reported on a significant correlation of p53 expression, especially for the use of preoperative CRT, while studies with the use of preoperative radiotherapy alone have reported that patients with a higher $\mathrm{p} 53$ expression had a shorter survival $(12,13)$. pRb strongly binds E2F and regulates the cell cycle by inducing G1 arrest (14). Results are conflicting for the expression of $\mathrm{pRb}$ and survival prognosis in patients with colorectal cancer treated with surgery without the use of preoperative CRT $(15,16)$. Furthermore, no study has reported on the clinical significance of $\mathrm{pRb}$ expression in patients treated with preoperative CRT. hMLH1 is a component of the DNA mismatch repair (MMR) system responsible for the detection and repair of DNA lesions, e.g., mismatches, small insertions and deletions (17,18). For LARC treated with preoperative CRT, conflicting findings in a few studies have been reported for the expression of hMLH1 and treatment response $(19,20)$, but no correlation with survival has been reported (20). MDM2 is a murine double-minute 2 oncogene product that forms a 
stable complex with wild-type and mutant p53 proteins (21). The MDM2 oncogene is amplified or overexpressed in many human types of cancer, and the overexpression of MDM2 is correlated with a poor prognosis $(22,23)$. Concerning MDM2 expression in LARC patients treated with preoperative CRT, no studies reported a significant relationship with tumor response or survival $(24,25)$.

Few reports exist regarding the significance of the biomarkers in patients treated with preoperative CRT for rectal cancer. In this study, we evaluated the expression of these biomarkers prior to preoperative CRT and attempted to correlate their expression with treatment outcome.

\section{Materials and methods}

Patients and pretreatment evaluation. Between March 2000 and May 2007, >100 patients with locally advanced rectal cancer received preoperative chemoradiotherapy at our institution. More than half of them received pretreatment pathological diagnosis at an outside referral hospital. Forty-five patients with available biopsy tissue specimens at our institution or nearby referral hospital were enrolled in the study. Pretreatment work-up included a complete history, physical examination, complete blood count, serum chemistry, determination of the carcinoembryonic antigen (CEA) level, chest radiography, an abdominal/pelvic CT scan and colonoscopy with biopsy. Informed consent was obtained from patients included in the study before treatment.

Treatment and follow-up. Radiation was delivered with 10-MV photons by the use of a three-field technique (posterior and both lateral fields). Radiotherapy was delivered 5 days/ week, once/day, at a dose of $1.8 \mathrm{~Gy} /$ day. Pelvic radiotherapy consisted of a median dose of 43.2 Gy in 24 fractions over 5 weeks, which was followed by a median boost dose of $7.2 \mathrm{~Gy}$, administered in 4 fractions to the primary tumor by the use of three fields. Chemotherapy consisted of 2 cycles of intravenous bolus 5 -FU (500 mg/m²/day) and leucovorin $\left(20 \mathrm{mg} / \mathrm{m}^{2} /\right.$ day $)$ for 5 days each, with or without cisplatin on the sixth day. At approximately seven weeks after the completion of CRT, the patients underwent definitive surgery. Surgical management included the use of a sphincter preservation approach whenever possible, by use of the total mesorectal excision technique. Each patient was provided with follow-up including a complete blood count, serum chemistry and determination of the CEA level every 3 months. Chest radiography and an abdominal/pelvic CT scan were performed every 6 months in the first 2 years. Follow-up was then performed every 6 months thereafter.

Immunohistochemical staining procedure. Biopsy specimens were obtained via a pretreatment endoscopy with 1 sample in each case. Specimens were routinely fixed in $10 \%$ buffered formalin and were embedded in paraffin. After reviewing hematoxylin and eosin-stained slides, serial sections from each block were used for immunohistochemistry. We carried out immunohistochemical staining with the use of the Microprobe Immuno/DNA stainer (Fisher Scientific, Pittsburgh, PA, USA). Immunohistochemical staining with primary antibodies for p53 (BP53-12, diluted 1:50; Novocastra
Laboratories, Newcastle, UK), human pRb (clone Rb1, diluted 1:40; Dako, Glostrup, Denmark), hMLH1 (G168-15, diluted 1:100; Zymed Laboratories, South San Francisco, CA, USA) and human MDM2 (clone IF2, diluted 1:100; Oncogene Research Products, Cambridge, MA, USA) was performed by use of the avidin-biotin-peroxidase complex method. Sections were deparaffinized and placed in a microwave oven with a $2.1 \%$ citric acid buffer solution ( $\mathrm{pH}$ 6.0) for $10 \mathrm{~min}$ to retrieve the antigens. Following microwave processing, the sections were incubated overnight at $4^{\circ} \mathrm{C}$ with primary antibodies. The use of a streptavidin-horseradish peroxidase detection system (Research Genetics, Huntsville, AL, USA) was then applied to capillary channels, followed by a 10 -min incubation at $50^{\circ} \mathrm{C}$. Reaction products were visualized with diaminobenzidine as a chromogen and slides were then counterstained with hematoxylin. Rectal cancer tissue strongly expressing p53 was used as a positive control for p53 and MDM2, while normal rectal epithelium adjacent to a tumor was used as a positive control for $\mathrm{pRb}$ and hMLH1. For negative controls, sections were treated similarly with omission of the primary antibody.

Assessment of p53, pRb, hMLH1 and MDM2 expression. Each slide was examined under the same magnification (x200, Vanox-S; Olympus, Tokyo, Japan) by one independent pathologist who moved the microscopic field randomly across specimens. Immunoreactivity was evaluated according to the frequency of positive nuclear staining. Semi-quantitative, 4-tier grading was based on the percentage of tumor cells that stained positive in the entire tumor boundary: 0, negative; 1, minimal ( $<10 \%$ staining); 2 , moderately stained (10-50\% staining) and 3, markedly stained ( $\geq 50 \%$ staining). Results were classified into two groups according to the number of positively stained cancer cells. Criteria for positive expression were defined as $>50 \%$ staining of the tumor tissue for hMLH1 and $\mathrm{p} 53$ expression, $>10 \%$ staining for $\mathrm{pRb}$ expression and $>0 \%$ for MDM2 expression.

Statistical analysis. The relationship between the clinicopathological factors and protein expression was analyzed by use of the Chi-square or Fisher's exact test, as appropriate. Overall survival (OS) was defined as the time from the starting date of preoperative CRT until the date the patient succumbed to any cause or of the last follow-up; disease-free survival (DFS) until the date of any recurrence as a first event and loco-regional recurrence-free survival (LRFS) until the date of the first detection of recurrence in the pelvis. Survival outcomes were calculated by use of the Kaplan-Meier method. The prognostic value of the protein expression was evaluated by use of the log-rank test for univariate analysis and the Cox proportional hazards model for multivariate analysis. $\mathrm{P}<0.05$ was considered as statistically significant. Statistical analyses were conducted by use of the SPSS version 17.0 statistical software (SPSS, Chicago, IL, USA).

\section{Results}

Immunohistochemical analysis of p53, pRb, hMLH1 and MDM2 expression. A positive expression of $\mathrm{p} 53, \mathrm{pRb}, \mathrm{hMLH} 1$ and MDM2 were found in 40, 46.7, 40 and $66.7 \%$ of the tissue specimens, respectively. Fig. 1 shows representative staining 

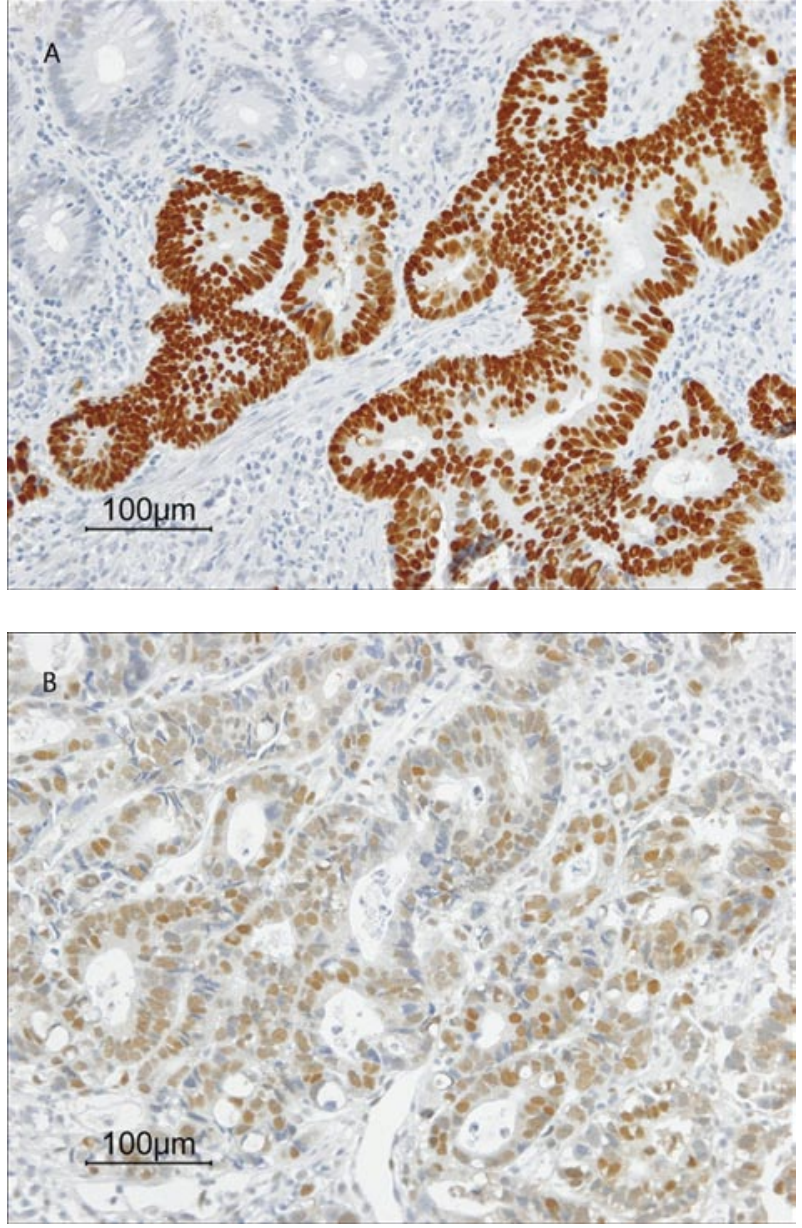
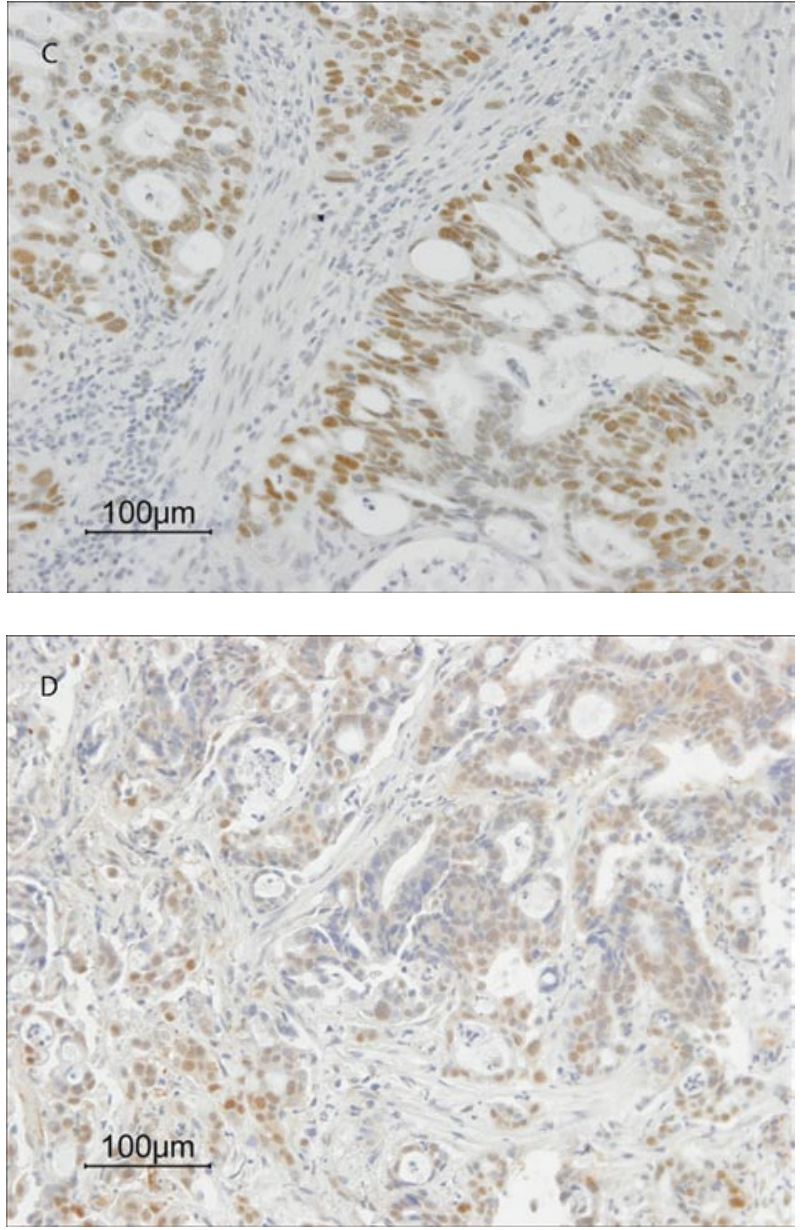

Figure 1. Positive immunohistochemical staining of (A) p53 expression, (B) pRb expression, (C) hMLH1 expression and (D) MDM2 expression. Original magnification, $\mathrm{x} 200$.

results of these proteins. Correlations between protein expression and patient clinicopathological factors are listed in Tables I and II. No significant correlation was observed for expression and clinicopathological factors including gender, age, preoperative clinical stage, postoperative pathological stage or primary tumor response. However, patients with a negative $\mathrm{pRb}$ expression achieved more complete tumor response and were of a younger age, with a marginal significance.

Relationship between protein expression and survival. After preoperative CRT, pathological complete response (CR) of primary tumors occurred in 10 patients $(22.2 \%)$. Pathological staging was as follows: pT0N0 in 7 patients (15.6\%), pT0N1-2 in 3 patients $(6.6 \%)$, pT1-2N0 in 7 patients $(15.6 \%)$, pT3-4N0 in 18 patients $(40 \%)$ and pT2-3N1-2 in 10 patients $(22.2 \%)$, including 1 patient with pT2N1M1. The follow-up range of the patients was 11-107 months (median 38.5). The 5-year OS, DFS and LRFS rates for the patients inclued in the study were 71.3, 66.1 and $60.9 \%$, respectively. The 5-year OS rates for pathological stages $0(n=7), I(n=7)$, II $(n=13)$, III $(n=13)$ and IV $(n=1)$ were $100,42.9,73.8,53.9$ and $0 \%$, respectively $(\mathrm{p}=0.11)$. Only p53 expression was a significant prognostic factor affecting $\mathrm{OS}$ in the univariate analysis (positive vs. negative expression, 45.8 vs. $86.2 \%$; $\mathrm{p}=0.02$; Fig. $2 \mathrm{~A}$ ). The expression of hMLH1 (positive vs. negative, 71.2 vs. $71.8 \%$; $\mathrm{p}=0.87$ ), MDM2 (posi- tive vs. negative, 72.7 vs. $65 \%$; $\mathrm{p}=0.31$ ) and $\mathrm{pRb}$ (positive vs. negative, 72.9 vs. $70 \%$; $\mathrm{p}=0.92$ ) did not affect OS significantly. The 5-year DFS rates for pathological stages 0, I, II, III and IV were $100,57.1,68.8,53.8$ and $0 \%$, respectively $(\mathrm{p}=0.000)$. p53 expression was a borderline significant prognostic factor affecting DFS (positive vs. negative, 50 vs. 77\%; $\mathrm{p}=0.06$; Fig. 2B). The expression of hMLH1 (positive vs. negative, 54.3 vs. $74.1 \%$; $\mathrm{p}=0.24$ ), MDM2 (positive vs. negative, 69.7 vs. $59.3 \%$; $\mathrm{p}=0.49$ ) and $\mathrm{pRb}$ (positive vs. negative, 59.3 vs. $70.8 \% ; \mathrm{p}=0.48$ ) did not affect DFS significantly. The 5-year LRFS rates for pathological stages 0 , I, II, III and IV were 85.7, 47.6, 69.7, 41 and $100 \%$, respectively $(\mathrm{p}=0.31)$. p53 expression was a borderline significant prognostic factor affecting LRFS (positive vs. negative, 45.1 vs. $70 \%$; $p=0.07$; Fig. $2 \mathrm{C}$ ). The expression of hMLH1 (positive vs. negative, 69.9 vs. $56.6 \%$; $=0.79$ ), MDM2 (positive vs. negative, 58.2 vs. 58.7\%; $\mathrm{p}=0.50$ ) and $\mathrm{pRb}$ (positive vs. negative, 58.8 vs. $62 \%$; $=0.85$ ) did not affect LRFS significantly.

Relationship of the clinicopathological parameters, protein expression and survival by multivariate analysis. Multivariate analysis was performed for OS with the use of 12 covariates. The covariates included age ( $\leq 55$ vs. $>55$ years), gender, clinical stage (I + II vs. III), tumor location from the anal verge $(<5$ vs. $\geq 5 \mathrm{~cm})$, interval between radiotherapy and surgery 
Table I. Clinicopathological characteristics of $\mathrm{p} 53$ and pRb protein expression.

\begin{tabular}{|c|c|c|c|c|c|c|}
\hline \multirow[t]{2}{*}{ Characteristics } & \multicolumn{2}{|c|}{ p53 } & \multirow[t]{2}{*}{ P-value } & \multicolumn{2}{|c|}{$\mathrm{pRb}$} & \multirow[t]{2}{*}{ P-value } \\
\hline & Positive & Negative & & Positive & Negative & \\
\hline Gender & & & 0.72 & & & 1.00 \\
\hline Male & 15 & 21 & & 17 & 19 & \\
\hline Female & 3 & 6 & & 4 & 5 & \\
\hline Age (years) & & & 0.39 & & & 0.08 \\
\hline$\leq 55$ & 9 & 10 & & 6 & 13 & \\
\hline$>55$ & 9 & 17 & & 15 & 11 & \\
\hline cStage $^{a}$ & & & 0.90 & & & 0.23 \\
\hline $\mathrm{I}+\mathrm{II}$ & 7 & 10 & & 6 & 11 & \\
\hline IIIb + IIIc & 11 & 17 & & 15 & 13 & \\
\hline pStage $^{b}$ & & & 0.38 & & & 0.12 \\
\hline 0 & 1 & 6 & & 1 & 6 & \\
\hline $\mathrm{I}+\mathrm{II}$ & 11 & 13 & & 14 & 10 & \\
\hline III + IV & 6 & 8 & & 6 & 8 & \\
\hline Response & & & 0.14 & & & 0.06 \\
\hline $\mathrm{CR}^{\mathrm{c}}$ & 2 & 8 & & 2 & 8 & \\
\hline Non-CR & 16 & 19 & & 19 & 16 & \\
\hline
\end{tabular}

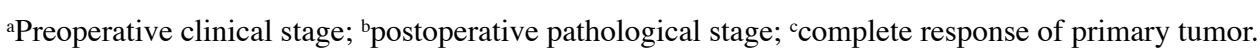

Table II. Clinicopathological characteristics of hMLH1 and MDM2 protein expression.

\begin{tabular}{|c|c|c|c|c|c|c|}
\hline \multirow[t]{2}{*}{ Characteristics } & \multicolumn{2}{|c|}{ hMLH1 } & \multirow[t]{2}{*}{ P-value } & \multicolumn{2}{|c|}{ MDM2 } & \multirow[t]{2}{*}{ P-value } \\
\hline & Positive & Negative & & Positive & Negative & \\
\hline Gender & & & 0.72 & & & 0.70 \\
\hline Male & 15 & 21 & & 23 & 13 & \\
\hline Female & 3 & 6 & & 7 & 2 & \\
\hline Age (years) & & & 0.81 & & & 0.14 \\
\hline$\leq 55$ & 8 & 11 & & 15 & 4 & \\
\hline$>55$ & 10 & 16 & & 15 & 11 & \\
\hline cStage $^{a}$ & & & 0.45 & & & 0.13 \\
\hline $\mathrm{I}+\mathrm{II}$ & 8 & 9 & & 9 & 8 & \\
\hline IIIb + IIIc & 10 & 18 & & 21 & 7 & \\
\hline pStage $^{b}$ & & & 0.41 & & & 0.26 \\
\hline 0 & 2 & 5 & & 3 & 4 & \\
\hline $\mathrm{I}+\mathrm{II}$ & 12 & 12 & & 16 & 8 & \\
\hline III + IV & 4 & 10 & & 11 & 3 & \\
\hline Response & & & 0.36 & & & 0.44 \\
\hline $\mathrm{CR}^{\mathrm{c}}$ & 3 & 7 & & 6 & 4 & \\
\hline Non-CR & 15 & 20 & & 24 & 11 & \\
\hline
\end{tabular}

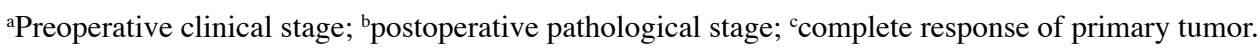

( $\leq 6$ vs. $>6$ weeks), sphincter-saving surgery or not, primary tumor response (CR or non-CR), pathological stage (0, I, II, III and IV) and expression of the four proteins. Age, MDM2 and p53 expression were significant factors affecting OS (Table III). No significant factor was determined for DFS or LRFS by multivariate analysis. 

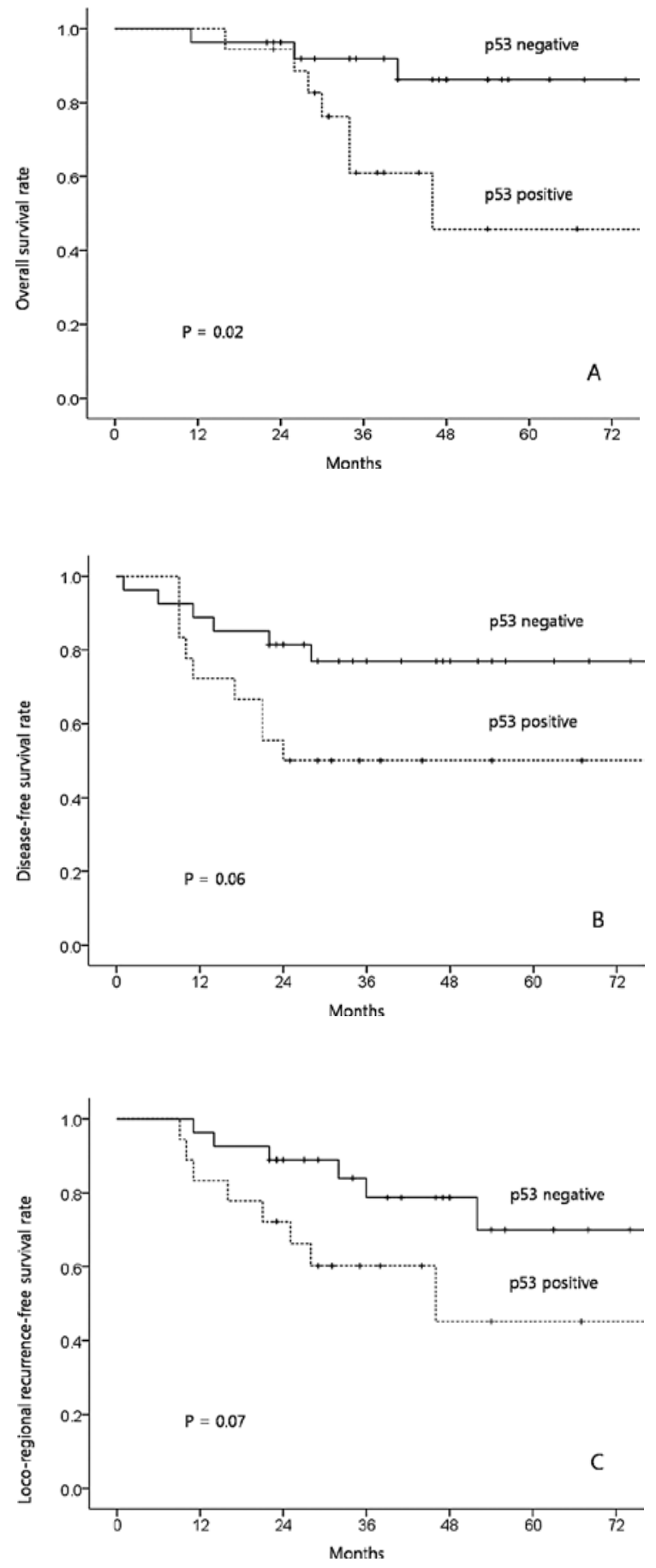

Figure 2. Univariate Kaplan-Meier survival analyses. (A) Overall, (B) diseasefree and (C) loco-regional recurrence-free survival according to the pattern of p53 expression.

\section{Discussion}

To identify patients that may achieve favorable response to treatment and are at risk for treatment failure, as well as to predict survival prognosis, a number of molecular markers were recently investigated in LARC patients. These molecular markers were examined to determine whether they would allow for the delivery of individualized treatment regimens. Epidermal growth factor expression has been associated with a poor response to preoperative chemoradiotherapy and worse DFS $(7,8)$. Rau et al reported that the expression of p21 appeared to predict worse DFS, while that of Ki-67 predicted better DFS in patients treated with neoadjuvant CRT (9). From the four proteins studied, MDM2 and p53 expression was found to be significantly related to OS. In addition, a negative $\mathrm{pRb}$ expression was associated with a more CR. Although p53 expression was found to have borderline significance for DFS or LRFS, we consider that the significance of p53 expression for DFS or LRFS may have improved had the analysis been conducted on a larger number of patients with a longer follow-up period.

The p53 gene facilitates DNA repair or apoptosis in response to DNA damage, whereas p53 gene mutations result in functional abnormalities that lead to radioresistance $(26,27)$. Shimoji et al reported that p53 immunoreactivity in esophageal carcinoma specimens, obtained prior to preoperative radiotherapy, was significantly correlated with radioresistance (27). In LARC patients treated with preoperative CRT, some studies have reported a poorer response in tumors with a higher p53 immunohistochemical staining of pretreatment biopsy specimens $(19,28)$, while other studies did not determine any correlation $(24,29)$. In the present study, pathological complete remission was reported in $22.2 \%$ of the patients. However, our study failed to show any statistically significant correlation between baseline p53 expression and the pathological response to CRT, although a trend for a higher pathological CR rate was observed in tumors negative for p53 expression (Table I). Concerning survival prognosis, studies of preoperative radiotherapy alone have reported that patients with a higher p53 expression showed shorter survival $(12,13)$. However, other studies have reported no relationship in LARC patients treated with preoperative CRT $(20,30)$. Our results showed that p53 was an independent prognostic factor affecting OS and a marginally significant factor for DFS or LFRS.

$\mathrm{pRb}$ strongly binds $\mathrm{E} 2 \mathrm{~F}$ and regulates the cell cycle by inducing G1 arrest (14). pRb is able to act as a survival factor in colonic epithelial cells by suppressing apoptosis.The

Table III. Cox proportional hazards model for overall survival.

\begin{tabular}{lccc}
\hline Characteristics & HR & 95\% CI & P-value \\
\hline Age (>55 vs. $\leq 55$ years) & 58.109 & $3.864-873.841$ & 0.003 \\
p53 (positive vs. negative) & 15.347 & $2.209-106.618$ & 0.006 \\
MDM2 (positive vs. negative) & 0.073 & $0.010-0.517$ & 0.009 \\
Sphincter-saving surgery (no vs. yes) & 4.187 & $0.847-20.703$ & 0.079
\end{tabular}

HR, hazard ratio; CI, confidence interval. 
overexpression of $\mathrm{pRb}$ in colorectal tumor cells can cause a loss of sensitivity to apoptotic signaling, resulting in aberrant cell survival and resistance to therapy (31). Our study showed that a trend for a higher pathological CR rate was observed in tumors with a negative pRb expression (Table I). Although the difference was not statistically significant, our results are in accordance with the observation that the overexpression of $\mathrm{pRb}$ may cause a loss of sensitivity to apoptotic signaling. It remains debatable whether $\mathrm{pRb}$ expression is of clinical significance in various types of cancer $(32,33)$. At resectable stages, most colorectal cancer types demonstrate an aberrant expression of $\mathrm{pRb}$ and/or $\mathrm{p} 16$. One study with surgery alone has reported that the aberrant expression of $\mathrm{pRb}$ and $\mathrm{p} 16$, alone and in combination, is associated with poor prognosis in patients with colorectal cancer (15), while other studies have reported no correlation with survival prognosis $(16,34)$. Our study demonstrated that $\mathrm{pRb}$ expression had no prognostic significance affecting survival, but had a marginal significance regarding preoperative CRT response, i.e., the negative $\mathrm{pRb}$ expression group showed a more $\mathrm{CR}$ of the primary tumor.

hMLH1 is a component of the DNA MMR system, which participates in DNA checkpoints and sends apoptotic signals (35). It is controversial as to whether radiation sensitivity is affected by the microsatellite instability or MLH1 status. Davis et al reported that MLH1-deficient human colon carcinoma cells show lower survival as compared to MMR-corrected human colon carcinoma cells because of a deficiency in the G2-M cell cycle checkpoint arrest after radiation treatment (36). In LARC patients treated with preoperative CRT, a few studies have shown conflicting results regarding response to CRT. Charara et al reported that patients with a lower expression of hMLH1 or higher microsatellite instability showed better treatment response (19), while Bertolini et al reported that patients treated with preoperative CRT and a positive hMLH1 expression had a higher CR rate (24.3 vs. 9.4\%; $\mathrm{p}=0.055$ ), but no correlation with survival (20). We previously reported that a low hMLH1 expression was found to be associated with poor prognosis in patients treated with definitive CRT for esophageal cancer (37). However, in the present study of LARC patients, we did not determine any significance of hMLH1 expression.

MDM2 is a murine double-minute 2 oncogene product that forms a stable complex with wild-type and mutant $\mathrm{p} 53$ proteins (21). MDM2 is responsible for shuttling p53 from the nucleus to the cytoplasm, promoting p53 degradation by proteasomes (38). MDM2 also binds with pRb, thus inhibiting the growth regulatory function of $\mathrm{pRb}$ in a $\mathrm{p} 53$-independent manner (39). The MDM2 oncogene is amplified or overexpressed in many human types of cancer and has a role in tumor growth through p53-dependent and -independent mechanisms. Moreover, MDM2 overexpression is correlated with a poor prognosis in many cancer types $(22,23)$. Kondo et al reported that disruption of the p53/MDM2/p14ARF pathway may frequently participate in colonic carcinogenesis. Moreover, the MDM2 expression status may be a factor in the prediction of potential invasion and the presence of liver metastases for colorectal carcinomas (22). Forslund et al found MDM2 to be amplified in $9 \%$ of the 284 colorectal cancers analyzed and MDM2 gene amplification was significantly correlated with advanced tumor stage (23). These investigators suggested that MDM2 is a promising target for cancer therapy in colorectal cancer for the use of small molecule MDM2 antagonists that can inhibit p53-MDM2 binding. Concerning the clinical significance of MDM2 expression in LARC, one study reported that MDM2 expression had no relationship with tumor response to preoperative CRT (24), while another study reported no correlation with survival in patients treated only with surgery (25). In the present study, a positive MDM2 expression was detected in 30 cases $(66.7 \%)$, showing a favorable prognosis with statistical significance in the multivariate analysis for OS. However, we did not consider its clinical significance, since MDM2 expression was not significant for any survival in the univariate analysis. Nevertheless, a further study is needed to elucidate whether the MDM2 oncoprotein is able to counteract or offset the poor prognostic role of mutant p53 protein, as well as what possible mechanism exists between them.

In conclusion, a negative p53 expression was found to be an independent prognostic marker for improved OS in this study. Patients with a negative $\mathrm{pRb}$ expression had a more $\mathrm{CR}$ to preoperative CRT. We suggest that the expression of p53 is a potential marker of survival that may be useful for selecting candidates from LARC patients for more tailored treatment.

\section{Acknowledgements}

This study was supported by the CRI-07074-1 grant from Chonnam National University Hospital Research Institute of Clinical Medicine. The authors thank Dr Young-Jin Kim, Professor in the Department of Surgery, Dr Byung-Sik Nah and Dr Woong-Ki Chung, Professors in the Department of Radiation Oncology, who provided and cared for the study patients, as well as Dr Jae-Uk Jeong, a resident in the Department of Radiation Oncology, who collected the data.

\section{References}

1. Janjan NA, Khoo VS, Abbruzzese J, et al: Tumor down-staging and sphincter preservation with preoperative chemoradiation in locally advanced rectal cancer: the M.D. Anderson Cancer Center experience. Int J Radiat Oncol Biol Phys 44: 1027-1038, 1999.

2. Kim JS, Cho MJ, Song KS and Yoon WH: Preoperative chemoradiation using oral capecitabine in locally advanced rectal cancer. Int J Radiat Oncol Biol Phys 54: 403-408, 2002.

3. Sauer R, Becker H, Hohenberger W, et al: Preoperative versus postoperative chemoradiotherapy for rectal cancer. N Engl J Med 351: 1731-1740, 2004.

4. Navarro M, Dotor E, Rivera F, et al: A Phase II study of preoperative radiotherapy and concomitant weekly irinotecan in combination with protracted venous infusion 5-fluorouracil, for resectable locally advanced rectal cancer. Int J Radiat Oncol Biol Phys 66: 201-205, 2006.

5. Kim YH, Kim DY, Kim TH, et al: Usefulness of magnetic resonance volumetric evaluation in predicting response to preoperative concurrent chemoradiotherapy in patients with resectable rectal cancer. Int J Radiat Oncol Biol Phys 62: 761-768, 2005.

6. Chang HJ, Jung KH, Kim DY, et al: Bax, a predictive marker for therapeutic response to preoperative chemoradiotherapy in patients with rectal carcinoma. Hum Pathol 36: 364-371, 2005.

7. Giralt J, De las Heras M, Cerezo L, et al: The expression of epidermal growth factor receptor results in a worse prognosis for patients with rectal cancer treated with preoperative radiotherapy: a multicenter, retrospective analysis. Radiother Oncol 74: 101-108, 2005.

8. Kim JS, Kim JM, Li S, et al: Epidermal growth factor receptor as a predictor of tumor downstaging in locally advanced rectal cancer patients treated with preoperative chemoradiotherapy. Int J Radiat Oncol Biol Phys 66: 195-200, 2006. 
9. Rau B, Sturm I, Lage H, et al: Dynamic expression profile of p21WAF1/CIP1 and Ki-67 predicts survival in rectal carcinoma treated with preoperative radiochemotherapy. J Clin Oncol 21: 3391-3401, 2003.

10. Rodel F, Capalbo G, Rodel C and Weiss C: Caveolin-1 as a prognostic marker for local control after preoperative chemoradiation therapy in rectal cancer. Int J Radiat Oncol Biol Phys 73: 846-852, 2009.

11. Levine AJ: p53, the cellular gatekeeper for growth and division. Cell 88: 323-331, 1997.

12. Adell G, Sun XF, Stal O, Klintenberg C, Sjodahl R and Nordenskjold B: p53 status: an indicator for the effect of preoperative radiotherapy of rectal cancer. Radiother Oncol 51: 169-174, 1999

13. Rebischung C, Gerard JP, Gayet J, Thomas G, Hamelin R and Laurent-Puig P: Prognostic value of p53 mutations in rectal carcinoma. Int J Cancer 100: 131-135, 2002.

14. Weinberg RA: The retinoblastoma protein and cell cycle control. Cell 81: 323-330, 1995.

15. Cui X, Shirai Y, Wakai T, Yokoyama N, Hirano S and Hatakeyama K: Aberrant expression of $\mathrm{pRb}$ and p16(INK4), alone or in combination, indicates poor outcome after resection in patients with colorectal carcinoma. Hum Pathol 35: 1189-1195, 2004.

16. Ioachim E: Expression patterns of cyclins D1, E and cyclindependent kinase inhibitors p21waf1/cip1, p27kip1 in colorectal carcinoma: correlation with other cell cycle regulators $(\mathrm{pRb}, \mathrm{p} 53$ and Ki-67 and PCNA) and clinicopathological features. Int J Clin Pract 62: 1736-1743, 2008.

17. Fink D, Aebi S and Howell SB: The role of DNA mismatch repair in drug resistance. Clin Cancer Res 4: 1-6, 1998.

18. Fishel R: The selection for mismatch repair defects in hereditary nonpolyposis colorectal cancer: revising the mutator hypothesis. Cancer Res 61: 7369-7374, 2001.

19. Charara M, Edmonston TB, Burkholder S, et al: Microsatellite status and cell cycle associated markers in rectal cancer patients undergoing a combined regimen of 5-FU and CPT-11 chemotherapy and radiotherapy. Anticancer Res 24: 3161-3167, 2004.

20. Bertolini F, Bengala C, Losi L, et al: Prognostic and predictive value of baseline and posttreatment molecular marker expression in locally advanced rectal cancer treated with neoadjuvan chemoradiotherapy. Int J Radiat Oncol Biol Phys 68: 1455-1461, 2007.

21. Momand J, Zambetti GP, Olson DC, George D and Levine AJ: The MDM2 oncogene product forms a complex with the $\mathrm{p} 53$ protein and inhibits p53-mediated transactivation. Cell 69: 1237-1245, 1992.

22. Kondo I, Iida S, Takagi Y and Sugihara K: MDM2 mRNA expression in the p53 pathway may predict the potential of invasion and liver metastasis in colorectal cancer. Dis Colon Rectum 51: 1395-1402, 2008.

23. Forslund A, Zeng Z, Qin LX, et al: MDM2 gene amplification is correlated to tumor progression but not to the presence of SNP309 or TP53 mutational status in primary colorectal cancers. Mol Cancer Res 6: 205-211, 2008.

24. Kudrimoti M, Lee EY, Kang Y, Ahmed M and Mohiuddin M: Genetic markers predictive of response to induction chemoradiotherapy for locally advanced rectal cancers. J Ky Med Assoc 105: 18-22, 2007.
25. Tzouvala M, Lazaris AC, Papatheodoridis GV, et al: Potential role of apoptosis and apoptotic regulatory proteins in colorectal neoplasia: correlations with clinico-pathological parameters and survival. Dig Dis Sci 53: 451-460, 2008.

26. Xia F, Wang X, Wang YH, Tsang NM, Yandell DW, Kelsey KT and Liber HL: Altered p53 status correlates with differences in sensitivity to radiation-induced mutation and apoptosis in two closely related human lymphoblast lines. Cancer Res 55: 12-15, 1995.

27. Shimoji H, Miyazato H, Nakachi A, et al: Expression of p53, bcl-2 and bax as predictors of response to radiotherapy in esophageal cancer. Dis Esophagus 13: 185-190, 2000.

28. Lin LC, Lee HH, Hwang WS, et al: p53 and p27 as predictors of clinical outcome for rectal-cancer patients receiving neoadjuvant therapy. Surg Oncol 15: 211-216, 2006.

29. Terzi C, Canda AE, Sagol O, et al: Survivin, p53 and Ki-67 as predictors of histopathologic response in locally advanced rectal cancer treated with preoperative chemoradiotherapy. Int J Colorectal Dis 23: 37-45, 2008.

30. Gosens MJ, Dresen RC, Rutten HJ, et al: Preoperative radiochemotherapy is successful also in patients with locally advanced rectal cancer who have intrinsically high apoptotic tumours. Ann Oncol 19: 2026-2032, 2008

31. Guy M, Moorghen M, Bond JA, Collard TJ, Paraskeva C and Williams AC: Transcriptional down-regulation of the retinoblastoma protein is associated with differentiation and apoptosis in human colorectal epithelial cells. Br J Cancer 84: 520-528, 2001.

32. Ikeguchi M, Ueda T, Fukuda K, Yamaguchi K, Tsujitani S and Kaibara N: Expression of the murine double-minute gene 2 oncoprotein in esophageal squamous cell carcinoma as a novel marker for lack of response to chemoradiotreatment. Am J Clin Oncol 25: 454-459, 2002.

33. Garcia del Muro X, Condom E, Vigues F, et al: p53 and p21 expression levels predict organ preservation and survival in invasive bladder carcinoma treated with a combined-modality approach. Cancer 100: 1859-1867, 2004.

34. McKay JA, Douglas JJ, Ross VG, et al: Analysis of key cell-cycle checkpoint proteins in colorectal tumours. J Pathol 196: 386-393, 2002.

35. Gong JG, Costanzo A, Yang HQ, Melino G, Kaelin WG Jr, Levrero $\mathrm{M}$ and Wang JY: The tyrosine kinase $\mathrm{c}-\mathrm{Abl}$ regulates p73 in apoptotic response to cisplatin-induced DNA damage. Nature 399: 806-809, 1999.

36. Davis TW, Wilson-Van Patten C, Meyers M, et al: Defective expression of the DNA mismatch repair protein, MLH1, alters G2-M cell cycle checkpoint arrest following ionizing radiation. Cancer Res 58: 767-778, 1998.

37. Nam TK, Lee JH, Cho SH, et al: Low hMLH1 expression prior to definitive chemoradiotherapy predicts poor prognosis in esophageal squamous cell carcinoma. Cancer Lett 260: 109-117, 2008.

38. Geyer RK, Yu ZK and Maki CG: The MDM2 RING-finger domain is required to promote p53 nuclear export. Nat Cell Biol 2: $569-573,2000$

39. Xiao ZX, Chen J, Levine AJ, Modjtahedi N, Xing J, Sellers WR and Livingston DM: Interaction between the retinoblastoma protein and the oncoprotein MDM2. Nature 375: 694-698, 1995. 